Pacific Journal of Mathematics

AN ALGEBRAICALLY DERIVED $q$-ANALOGUE OF A

Th 


\title{
AN ALGEBRAICALLY DERIVED $q$-ANALOGUE OF A CHARACTER SUM ASSOCIATED WITH A CLASS OF SEMIREGULAR PERMUTATIONS
}

\author{
G. E. ANDREWS AND D. M. JACKSON
}

\begin{abstract}
The group algebra of the symmetric group can be used to determine the cycle structure of permutations which are obtained as products of designated conjugacy classes. Such matters arise, for example, in certain topological questions and in the embedding of graphs on orientable surfaces. We consider a set of permutations restricted by cycle structure, and use basic hypergeometric series to derive $q$-analogues associated with the generating functions for the numbers of such permutations. The expressions which are derived pose a number of combinatorial questions about their connexion with the Hecke algebra of the symmetric group.
\end{abstract}

1. Introduction and background to the problem. A permutation is said to be $p$-semiregular if all of its cycles have the same length $p$. In this paper we derive a $q$-analogue for the number $e(k, p)$ of $p$ semiregular permutations, with $k$ cycles, which are the product of a designated full-cycle and a fixed point free involution. Such permutations occur in several areas of combinatorial theory ([7], [8]).

The $q$-analogue involves a new summable almost poised terminating ${ }_{3} \phi_{2}$, discovered independently by Bressoud [4]. This (see (9)) is given in $\S 2$, together with other known basic hypergeometric summation theorems included for completeness. In $\S \S 3,4$ and 5 we consider the cases $p=3,4,6$, respectively. In a sense to be explained in $\S 6$, these are the most interesting cases. Of the expressions we give for $q$-analogues, namely, $M_{q}$ in Theorem 3.1, $J_{q}$ in Theorem 4.1, $G_{q}$ in Theorem 4.2 and $L_{q}$ in Theorem 5.1, the one which specialises precisely when $q=1$ to the correct expression (1) is given in Theorem 4.2.

For permutation problems, $q$-analogues of generating series often appear when a set of permutations is enumerated with respect to the inversion number or the major index (see [6]), marked by $q$. Since these are not class functions for the symmetric group, they cannot be used in conjunction with the group algebra of $S_{n}$ to derive our result. However, the group algebra of the symmetric group is abstractly 
isomorphic to the Hecke algebra associated with $S_{n}$, and explicit (inequivalent) isomorphisms have been given by Wenzl [12] and Lusztig [10]. The latter involves the Kazhdan-Lusztig polynomials. Our result indicates that combinatorial information may be preserved by one or the other of these explicit isomorphisms.

If $\theta$ is a partition of $N$ we write $\theta \vdash N$, and the corresponding conjugacy class if $S_{N}$ is denoted by $\mathscr{C}_{\theta}$. This is the set of all permutations in $S_{N}$ with $i_{j} j$-cycles, $j=1, \ldots$, where $\theta=\left[1^{i_{1}} 2^{i_{2}} \ldots\right]$. The size of $\mathscr{C}_{\theta}$ is denoted by $h^{\theta}$. The irreducible (ordinary) character associated with $\mathscr{C}_{\theta}$ is denoted by $\chi^{\theta}$, its value at any element of $\mathscr{C}_{\theta}$ where $\alpha \vdash N$ is denoted by $\chi_{\alpha}^{\theta}$, and its degree is denoted by $f^{\theta}$.

To derive an expression for $e(k, p)$, we use the following combinatorial facts which can be deduced from the group algebra $\mathbb{C} S_{N}$ over $\mathbb{C}$. The proofs are given in [8] where use is made of the fact that $K_{\theta}=\sum_{g \in \mathscr{C}_{\theta}} g \in \mathbb{C} S_{n}$ can be expressed as a linear combination of orthogonal idempotents in the centre of $\mathbb{C} S_{n}$ since the latter is semisimple [11]. Explicit use is also made of properties of $\chi^{\theta}$ at $g \in \mathscr{C}_{[k p]}$, $g \in \mathscr{C}_{\left[k^{p}\right]}$, and $g \in \mathscr{C}_{\left[2^{\frac{1}{2} k p}\right]}$.

Proposition 1.1. Let

$$
T(k, p)=\sum_{\theta \vdash k p} \frac{1}{f^{\theta}} \chi_{[k p]}^{\theta} \chi_{\left[k^{p}\right]}^{\theta} \chi_{\left[2^{k p / 2}\right]}^{\theta}
$$

Then

$$
e(k, p)=h^{[k p / 2]} h^{\left[k^{p}\right]} \frac{T(k, p)}{(k p) !}
$$

LEMMA 1.2.

(1) $T(k, p)$

$$
=\sum_{i=0}^{k p-1} \frac{(-1)^{i}}{\left(\begin{array}{c}
k p-1 \\
i
\end{array}\right)}\left(\left[y^{i}\right] \frac{\left(1-y^{2}\right)^{\frac{1}{2} k p}}{1+y}\right)\left(\left[y^{i}\right] \frac{\left(1-(-y)^{p}\right)^{k}}{1+y}\right)
$$

Explicit expressions for $e(k, p)$ can be deduced from (1). For example

$$
\begin{aligned}
& T(2 n-1,4)=4^{3 n-2}\left(\begin{array}{c}
2 n \\
n
\end{array}\right)\left(\begin{array}{c}
8 n-4 \\
4 n-2
\end{array}\right)^{-1} \\
& T(4 n+2,3)=12\left(2^{4} \cdot 3^{3}\right)^{n}\left(\begin{array}{c}
4 n+2 \\
n+1
\end{array}\right)\left(\begin{array}{c}
12 n+6 \\
6 n+3
\end{array}\right)^{-1} .
\end{aligned}
$$


Our purpose now is to derive a $q$-analogue of the expression for $T(k, p)$. We shall see that Theorem 5.2 is an exact $q$-analogue of Lemma 2.2. For this, the basic hypergeometric summation theorems given in $\S 2$ are needed.

2. Basic hypergeometric formulas. To evaluate the sums considered in the later sections, we require some observations on the basic hypergeometric series ${ }_{3} \phi_{2}$ defined by

$$
{ }_{3} \phi_{2}\left(\begin{array}{c}
a, b, c ; q, t \\
d, e
\end{array}\right)=\sum_{n=0}^{\infty} \frac{(a ; q)_{n}(b ; q)_{n}(c ; q)_{n} t^{n}}{(q ; q)_{n}(d ; q)_{n}(e ; q)_{n}}
$$

where

$$
(A ; q)_{n}=(A)_{n}=(1-A)(1-A q) \cdots\left(1-A q^{n-1}\right) .
$$

We also require the $q$-binomial theorem (Thm. 2.1, [3]);

$$
(A ; q)_{N}=\sum_{j=0}^{N}\left[\begin{array}{c}
N \\
j
\end{array}\right](-A)^{j} q^{j(j-1) / 2}
$$

where

$$
\left[\begin{array}{c}
N \\
j
\end{array}\right]_{r}=\frac{\left(1-q^{N r}\right)\left(1-q^{(N-1) r}\right) \cdots\left(1-q^{(N-j+1) r}\right)}{\left(1-q^{j r}\right)\left(1-q^{(j-1) r}\right) \cdots\left(1-q^{r}\right)}
$$

and we write just $\left[\begin{array}{l}n \\ j\end{array}\right]$ when $r=1$.

Two ${ }_{3} \phi_{2}$ summations are needed. The first is the $q$-analogue of Dixon's Theorem ([5], [9], [2, eq. (5.7), p. 216]). If $N$ is even and $\alpha$ is 2 or 4 then

$$
\begin{aligned}
{ }_{3} \phi_{2}\left(\begin{array}{c}
q^{-N}, b, c ; q, q^{(\alpha-N) / 2} / b c \\
q^{1-N} / b, q^{1-N} / c
\end{array}\right) \\
=\frac{q^{N(\alpha-4) / 4}\left(q^{1+N / 2}\right)_{N / 2}\left(q^{N / 2} b c\right)_{N / 2}}{\left(b q^{N / 2}\right)_{N / 2}\left(c q^{N / 2}\right)_{N / 2}} .
\end{aligned}
$$

The second result is due to Bressoud ([4]; eq. (1.4) for $\alpha=1$, eq. (1.10) for $\alpha=3$ ). If $N$ is odd and $\alpha$ is 1 or 3 then

$$
\begin{aligned}
{ }_{3} \phi_{2}\left(\begin{array}{c}
q^{1-N}, b, c ; q, q^{(\alpha-N) / 2} / b c \\
q^{1-N} / b, q^{1-N} / c
\end{array}\right) \\
=\frac{\left(q^{(N+1) / 2}\right)_{(N-1) / 2}\left(q^{(N+1) / 2} b c\right)_{(N-1) / 2}}{\left(b q^{(N+1) / 2}\right)_{(N-1) / 2}\left(c q^{(N+1) / 2}\right)_{(N-1) / 2}} .
\end{aligned}
$$

The integer-valued functions $(\varepsilon(n, i), \lambda(n, i), \psi(n, i), \mu(n, i))$, which are introduced without further comment in $\S \S 3,4$ and 5 , have been constructed to be consistent with the application of whichever of the above summation theorems is appropriate to the particular case. 
3. The modulus 3 case. We begin by considering $\varepsilon(n, i)$ for integers $n \geq 1$ and $i \geq 0$ which satisfy the following conditions: for all $n \geq 1$ :

$$
\text { (10) } \begin{aligned}
\varepsilon(n, 3 i+2) & =\varepsilon(n, 3(n-i-1))+6\left(\begin{array}{c}
n-i \\
2
\end{array}\right)-6\left(\begin{array}{c}
i+1 \\
2
\end{array}\right) \\
& =\varepsilon(n, 3(n-i-1))+6\left(\begin{array}{l}
n \\
2
\end{array}\right)-6 n i
\end{aligned}
$$

for $n$ even and positive

$$
\text { (11) } \begin{aligned}
\varepsilon(n, 3 i+1) & =\varepsilon(n, 3(n-i-1))+6\left(\begin{array}{c}
n-i \\
2
\end{array}\right)-6\left(\begin{array}{c}
i+1 \\
2
\end{array}\right) \\
& =\varepsilon(n, 3(n-i-1))+6\left(\begin{array}{l}
n \\
2
\end{array}\right)-6 n i
\end{aligned}
$$

for $n$ odd and positive with $\alpha=1$ or 3

$$
\begin{aligned}
\varepsilon(n, 3 i)= & -6(n-1) i-6 i+3 i(3 n-1) \\
& -\left(\begin{array}{c}
3 i \\
2
\end{array}\right)+\frac{3}{2}(\alpha-n) i-3 i \\
= & \frac{3}{2}(\alpha+n) i-\left(\begin{array}{c}
3 i \\
2
\end{array}\right)-6 i ;
\end{aligned}
$$

and for $n$ odd and positive with $\beta=2$ or 4

$$
\begin{aligned}
\varepsilon(n, 3 i+1)= & -6(n-1) i+(3 i+1)(3 n-1) \\
& -6 i-\left(\begin{array}{c}
3 i+1 \\
2
\end{array}\right)+\frac{3}{2}(\beta-n+1) i-6 i \\
= & \frac{3}{2}(\beta+n-1) i+3 n-1-\left(\begin{array}{c}
3 i+1 \\
2
\end{array}\right)-6 i .
\end{aligned}
$$

The first portion of each of (10)-(13) is designed to facilitate our proof of Theorem 3.1. We also note that (10) and (11) do not fully define $\varepsilon(n, i)$ when $n$ is even; indeed, when $n$ is even the $\varepsilon(n, i)$ can take any values which fulfill (10) and (11).

THEOREM 3.1. Let $\alpha=1$ or $3, \beta=2$ or 4 and

$$
M_{q}(n)=\sum_{i=0}^{3 n-1} \frac{(-1)^{i}}{\left[\begin{array}{c}
3 n-1 \\
i
\end{array}\right]}\left\{\left[y^{i}\right] \frac{\left(y^{3} ; q^{3}\right)_{n}}{1-y}\right\}^{2} q^{\varepsilon(n, i)}
$$

where the $\varepsilon(n, i)$ satisfy (10)-(13). Then, for $n$ even

$$
M_{q}(n)=0,
$$


and for $n$ odd

(16)

$$
\begin{aligned}
M_{q}(n)= & \left(2-\frac{(1-q) q^{(3 / 4)(n-1) \beta+2}}{1-q^{(3 n+1) / 2}}\right) \\
& \times \frac{\left(q^{(3 / 2)(n+1)} ; q^{3}\right)_{(n-1) / 2}\left(q^{(3 / 2)(n+3)} ; q^{3}\right)_{(n-1) / 2}}{\left(q^{(3 n+5) / 2} ; q^{3}\right)_{(n-1) / 2}\left(q^{(3 n+7) / 2} ; q^{3}\right)_{(n-1) / 2}}
\end{aligned}
$$

Proof. Clearly

(17) $M_{q}(n)=\sum_{i=0}^{3 n-1} \frac{(-1)^{i} q^{\varepsilon(n, i)}}{\left[\begin{array}{c}3 n-1 \\ i\end{array}\right]}\left\{\left[y^{i}\right]\left(1+y+y^{2}\right)\left(y^{3} q^{3} ; q^{3}\right)_{n-1}\right\}^{2}$

$$
\begin{aligned}
= & \sum_{i=0}^{n-1} \frac{(-1)^{i} q^{\varepsilon(n, 3 i)}}{\left[\begin{array}{c}
3 n-1 \\
3 i
\end{array}\right]}\left(\left[\begin{array}{c}
n-1 \\
i
\end{array}\right]_{3} q^{3\left(\begin{array}{c}
i+1 \\
2
\end{array}\right)}\right)^{2} \\
& -\sum_{i=0}^{n-1} \frac{(-1)^{i} q^{\varepsilon(n, 3 i+1)}}{\left[\begin{array}{c}
3 n-1 \\
3 i+1
\end{array}\right]}\left(\left[\begin{array}{c}
n-1 \\
i
\end{array}\right]_{3} q^{3\left(\begin{array}{c}
i+1 \\
2
\end{array}\right)}\right)^{2} \\
& +\sum_{i=0}^{n-1} \frac{(-1)^{i} q^{\varepsilon(n, 3 i+2)}}{\left[\begin{array}{c}
3 n-1 \\
3 i+2
\end{array}\right]}\left(\left[\begin{array}{c}
n-1 \\
i
\end{array}\right]_{3} q^{3\left(\begin{array}{c}
(+1 \\
2
\end{array}\right)}\right)^{2} .
\end{aligned}
$$

By $(10)$, we see that when $n$ is even the $(n-i-1)$ st term in the third sum cancels the $i$ th term in the first sum, while the $i$ th and $(n-i-1)$ st terms in the second sum cancel. Hence (15) is true.

On the other hand, when $n$ is odd the first sum is identical with the third. Furthermore, we may rewrite each sum in terms of rising $q$-factorials since

$$
\left[\begin{array}{l}
A \\
B
\end{array}\right]_{r}=\frac{\left(q^{-r A} ; q^{r}\right)_{B}}{\left(q^{r} ; q^{r}\right)_{B}}(-1)^{B} q^{r A B-r\left(\begin{array}{l}
B \\
2
\end{array}\right)}
$$

and

$$
\begin{aligned}
(A ; q)_{3 m+t} & =(A)_{t}\left(A q^{t}\right)_{3 m} \\
& =(A)_{t}\left(A q^{t} ; q^{3}\right)_{m}\left(A q^{t+1} ; q^{3}\right)_{m}\left(A q^{t+2} ; q^{3}\right)_{m}
\end{aligned}
$$


Therefore, when $n$ is odd

(20)

$$
\begin{aligned}
M_{q}(n)= & 2_{3} \phi_{2}\left(\begin{array}{c}
q^{3(1-n)}, q, q^{2} ; q^{3}, q^{3((\alpha-n) / 2-1)} \\
q^{2-3 n}, q^{1-3 n}
\end{array}\right)+\frac{(1-q)}{\left(1-q^{1-3 n}\right)} \\
& \cdot{ }_{3} \phi_{2}\left(\begin{array}{c}
q^{3(1-n)}, q^{2}, q^{4} ; q^{3}, q^{3((\beta-n+1) / 2-2)} \\
q^{4-3 n}, q^{2-3 n}
\end{array}\right) \\
= & 2 \frac{\left(q^{(3 / 2)(n+1)} ; q^{3}\right)_{(n-1) / 2}\left(q^{(3 / 2)(n+3)} ; q^{3}\right)_{(n-1) / 2}}{\left(q^{(3 n+5) / 2} ; q^{3}\right)_{(n-1) / 2}\left(q^{(3 n+7) / 2} ; q^{3}\right)_{(n-1) / 2}} \\
& -q^{(3 / 4)(n-1) \beta+2}(1-q) \\
& \times \frac{\left(q^{(3 / 2)(n+1)} ; q^{3}\right)_{(n-1) / 2}\left(q^{(3 / 2)(n+3)} ; q^{3}\right)_{(n-1) / 2}}{\left(q^{(3 n+1) / 2} ; q^{3}\right)_{(n+1) / 2}\left(q^{(3 n+5) / 2} ; q^{3}\right)_{(n-1) / 2}}
\end{aligned}
$$

by (9) and (8) respectively.

4. The modulus 4 case. We begin by considering $\lambda(n, i)$, which may be arbitrary for $i$ odd and is given by

$$
\begin{aligned}
\lambda(n, 4 i) & =-8 i^{2}+2 i+2 n i, \\
\lambda(n, 4 i+2) & =-8 i^{2}-2 i+2 n i
\end{aligned}
$$

for $i$ even.

THEOREM 4.1. Let

$$
\begin{aligned}
J_{q}(n)=\sum_{i=0}^{4 n-2} \frac{(-1)^{i} q^{\lambda(n, i)}}{\left[\begin{array}{c}
4 n-2 \\
i
\end{array}\right]}\left\{\left[y^{i}\right]\left(y^{2} ; q^{2}\right)_{2 n-1}\right\} \\
\times\left\{\left[y^{i}\right]\left(y^{4} ; q^{4}\right)_{n-1}\left(1+y^{2}\right)\right\} .
\end{aligned}
$$

Then $J_{q}(n)$ is zero if $n$ is odd, and if $n$ is even

$$
J_{q}(n)=\frac{2 q\left(q^{2 n} ; q^{4}\right)_{n / 2}\left(q^{2 n+4} ; q^{4}\right)_{(n-2) / 2}}{\left(q^{2 n+1} ; q^{2}\right)_{n-1}} .
$$

Proof. The terms in $J_{q}(n)$ with $i$ odd must be zero since each term in braces is the $i$ th coefficient of an even polynomial. Furthermore, the final term in brackets has a different form depending on whether 
$i \equiv 0$ or $2(\bmod 4)$. Therefore

$$
\begin{aligned}
& J_{q}(n)=\sum_{i=0}^{n-1}(-1)^{i} q^{\lambda(n, 4 i)+6 i^{2}-4 i} \frac{\left[\begin{array}{c}
n-1 \\
i
\end{array}\right]_{4}\left[\begin{array}{c}
2 n-1 \\
2 i
\end{array}\right]_{2}}{\left[\begin{array}{c}
4 n-2 \\
4 i
\end{array}\right]} \\
& -\sum_{i=0}^{n-1}(-1)^{l} q^{\lambda(n, 4 i+2)+6 l^{2}} \frac{\left[\begin{array}{c}
n-1 \\
i
\end{array}\right]_{4}\left[\begin{array}{c}
2 n-1 \\
2 i+1
\end{array}\right]_{2}}{\left[\begin{array}{c}
4 n-2 \\
4 i+2
\end{array}\right]} \\
& =\sum_{i=0}^{n-1}(-1)^{l} q^{2 i(n-i-1)} \frac{\left[\begin{array}{c}
n-1 \\
i
\end{array}\right]_{4}\left[\begin{array}{c}
2 n-1 \\
2 i
\end{array}\right]_{2}}{\left[\begin{array}{c}
4 n-2 \\
4 l
\end{array}\right]} \\
& -\sum_{i=0}^{n-1}(-1)^{l} q^{2 i(n-i-1)} \frac{\left[\begin{array}{c}
n-1 \\
i
\end{array}\right]_{4}\left[\begin{array}{c}
2 n-1 \\
2 l+1
\end{array}\right]_{2}}{\left[\begin{array}{c}
4 n-2 \\
4 i+2
\end{array}\right]} \text {. }
\end{aligned}
$$

Now let us replace $i$ by $n-i-1$ in the second sum. Thus

$$
J_{q}(n)=\left(1-(-1)^{n-1}\right) \sum_{i=0}^{n-1}(-1)^{i} q^{2 i(n-i-1)} \frac{\left[\begin{array}{c}
n-1 \\
i
\end{array}\right]_{4}\left[\begin{array}{c}
2 n-1 \\
2 i
\end{array}\right]_{2}}{\left[\begin{array}{c}
4 n-2 \\
4 i
\end{array}\right]} .
$$

Thus $J_{q}(n)=0$ if $n$ is odd. If $n$ is even,

$$
\begin{aligned}
J_{q}(n) & =2_{3} \phi_{2}\left(\begin{array}{c}
q^{-4 n+4}, q, q^{3} ; q^{4}, q^{-2 n} \\
q^{-4 n+5}, q^{-4 n+3}
\end{array}\right) \\
& =\frac{2 q\left(q^{2 n} ; q^{4}\right)_{n / 2}\left(q^{2 n+4} ; q^{4}\right)_{(n-2) / 2}}{\left(q^{2 n+1} ; q^{2}\right)_{n-1}}
\end{aligned}
$$

by (8), and this establishes (24).

While Theorem 4.1 relied only on the $q$-analogue of Dixon's summation, Theorem 4.2 requires the additional summation theorem given in (9).

Here we must define $\psi(n, i)$ for $n \geq 1, i \geq 0$ by

$$
\begin{aligned}
\psi(n, 4 i) & =2 i(\alpha+n-4 i-3), \\
\psi(n, 4 i+1) & =2 i(-\beta+n-4 i)+(n-1)(\beta-2), \\
\psi(n, 4 i+2) & =2 i(\beta+n-4 i-8)-(n-1)(\beta-4)-2, \\
\psi(n, 4 i+3) & =2 i(-\alpha+n-4 i-5)+2 \alpha(n-1)-2 .
\end{aligned}
$$

THEOREM 4.2. Let $\alpha$ be either 1 or 3 , and $\beta$ be either 2 or 4, and let

$$
\text { (30) } G_{q}(n)=\sum_{i=0}^{4 n-1} \frac{(-1)^{i} q^{\psi(n, i)}}{\left[\begin{array}{c}
4 n-1 \\
i
\end{array}\right]}\left\{\left[y^{i}\right] \frac{\left(y^{2} ; q^{2}\right)_{2 n}}{1+y}\right\}\left\{\left[y^{i}\right] \frac{\left(y^{4} ; q^{4}\right)_{n}}{1+y}\right\} \text {. }
$$


Then $G_{q}(n)=0$ if $n$ is even, and if $n$ is odd

$$
G_{q}(n)=2 q\left(1-q^{2 n}\right) \frac{\left(q^{2 n+2} ; q^{4}\right)_{(n-1) / 2}\left(q^{2 n+6} ; q^{4}\right)_{(n-1) / 2}}{\left(q^{2 n+3} ; q^{4}\right)_{(n-1) / 2}\left(q^{2 n+1} ; q^{4}\right)_{(n+1)}}
$$

Proof. Noting that

$$
\left[y^{i}\right] \frac{\left(y^{2} ; q^{2}\right)_{2 n}}{1+y}=\left[y^{i}\right](1-y)\left(y^{2} q^{2} ; q^{2}\right)_{2 n-1}
$$

and

$$
\left[y^{i}\right] \frac{\left(y^{4} ; q^{4}\right)_{n}}{1+y}=\left[y^{i}\right]\left(1+y^{2}\right)(1-y)\left(y^{4} q^{4} ; q^{4}\right)_{n-1}
$$

we see that we must split the sum for $G_{q}(n)$ into four parts depending on the residue of $i(\bmod 4)$. Hence

$$
\begin{aligned}
G_{q}(n)= & \sum_{i=0}^{n-1}(-1)^{i} q^{2 i(\alpha+n-i-1)} \frac{\left[\begin{array}{c}
n-1 \\
i
\end{array}\right]_{4}\left[\begin{array}{c}
2 n-1 \\
2 i
\end{array}\right]_{2}}{\left[\begin{array}{c}
4 n-1 \\
4 i
\end{array}\right]} \\
& -\sum_{i=0}^{n-1}(-1)^{i} q^{2 i(-\beta+n-i+2)+(\beta+2)(n-1)} \frac{\left[\begin{array}{c}
n-1 \\
i
\end{array}\right]_{4}\left[\begin{array}{c}
2 n-1 \\
2 i
\end{array}\right]_{2}}{\left[\begin{array}{c}
4 n-2 \\
4 i+1
\end{array}\right]} \\
& -\sum_{i=0}^{n-1}(-1)^{i} q^{2 i(\beta+n-i-4)-(n-1)(\beta-8)} \frac{\left[\begin{array}{c}
n-1 \\
i
\end{array}\right]_{4}\left[\begin{array}{c}
2 n-1 \\
2 i+1
\end{array}\right]_{2}}{\left[\begin{array}{c}
4 n-1 \\
4 i+2
\end{array}\right]} \\
& +\sum_{i=0}^{n-1}(-1)^{i} q^{2 i(-\alpha+n-i-1)+2 \alpha(k-1)} \frac{\left[\begin{array}{c}
n-1 \\
i
\end{array}\right]_{4}\left[\begin{array}{c}
2 n-1 \\
2 i+1
\end{array}\right]_{2}}{\left[\begin{array}{c}
4 n-1 \\
4 i+3
\end{array}\right]}
\end{aligned}
$$

If $i$ is replaced by $n-i-1$ in the second and fourth sums, then

$$
\begin{aligned}
G_{q}(n)= & \delta_{n} \sum_{i=0}^{n-1}(-1)^{i} q^{2 i(\alpha+n-i-1)} \frac{\left[\begin{array}{c}
n-1 \\
i
\end{array}\right]_{4}\left[\begin{array}{c}
2 n-1 \\
2 i
\end{array}\right]_{2}}{\left[\begin{array}{c}
4 n-1 \\
4 i
\end{array}\right]} \\
& -\delta_{n} \sum_{i=0}^{n-1}(-1)^{i} q^{2 i(\beta+n-i-4)-(n-1)(\beta-4)} \frac{\left[\begin{array}{c}
n-1 \\
i
\end{array}\right]_{4}\left[\begin{array}{c}
2 n-1 \\
2 i+1
\end{array}\right]_{2}}{\left[\begin{array}{c}
4 n-1 \\
4 i+2
\end{array}\right]}
\end{aligned}
$$

where $\delta_{n}=1+(-1)^{n-1}$. Therefore $G_{q}(n)$ is clearly 0 if $n$ is even. 
If $n$ is odd,

(34)

$$
\begin{aligned}
G_{q}(n)= & 2_{3} \phi_{2}\left(\begin{array}{c}
q^{-4 n+4}, q, q^{3} ; q^{4}, q^{2(\alpha-n-2)} \\
q^{-4 n+3}, q^{-4 n+1}
\end{array}\right) \\
& -2 \frac{q^{(\beta-4)(1-n)}(1-q)}{\left(1-q^{4 n-1}\right)}{ }_{3} \phi_{2}\left(\begin{array}{c}
q^{-4 n+4}, q^{5}, q^{3} ; q^{4}, q^{2(\beta-n-3)} \\
q^{-4 n+3}, q^{-4 n+5}
\end{array}\right) \\
= & \frac{2\left(q^{2 n+2} ; q^{4}\right)_{(n-1) / 2}\left(q^{2 n+6} ; q^{4}\right)_{(n-1) / 2}}{\left(q^{2 n+3} ; q^{2}\right)_{n-1}} \\
& -\frac{2(1-q)\left(q^{2 n+2} ; q^{4}\right)_{(n-1) / 2}\left(q^{2 n+6} ; q^{4}\right)_{(n-1) / 2}}{\left(q^{2 n+1} ; q^{2}\right)_{n}} \\
= & \frac{2\left(q^{2 n+2} ; q^{4}\right)_{(n-1) / 2}\left(q^{2 n+6} ; q^{4}\right)_{(n-1) / 2}\left(\left(1-q^{2 n+1}\right)-(1-q)\right)}{\left(q^{2 n+1} ; q^{2}\right)_{n}} \\
= & \frac{2 q\left(1-q^{2 n}\right)\left(q^{2 n+2} ; q^{4}\right)_{(n-1) / 2}\left(q^{2 n+6} ; q^{4}\right)_{(n-1) / 2}}{\left(q^{2 n+1} ; q^{2}\right)_{n}} .
\end{aligned}
$$

as desired.

5. The modulus 6 case. We now consider $\mu(n, i)$, which, for $n$, $i \geq 0$, satisfy the following requirements: if $n$ is odd, then

$$
\begin{aligned}
\mu(n, 6 i) & =\mu(n, 6(n-i))+15(n-i)^{2}-6(n-i)-15 i^{2}+6 i \\
& =\mu(n, 6(n-i))+15 n^{2}-6 n-30 n i
\end{aligned}
$$

If $n$ is even then, for $\gamma=2$ or 4 ,

$$
\mu(n, 6 i)=3(\gamma+n) i-\left(\begin{array}{c}
6 i+1 \\
2
\end{array}\right) .
$$

\section{THEOREM 5.1. Let}

$$
L_{q}(n)=\sum_{i=0}^{6 n} \frac{(-1)^{i} q^{\mu(n, i)}}{\left(\begin{array}{c}
6 n \\
i
\end{array}\right)}\left\{\left[y^{i}\right]\left(y^{3} ; q^{3}\right)_{2 n}\right\}\left\{\left[y^{i}\right]\left(y^{2} ; q^{2}\right)_{3 n}\right\}
$$

Then $L_{q}(n)$ is zero if $n$ is odd, and, if $n$ is even

$$
L_{q}(n)=\frac{q^{\frac{3}{2} n(\gamma-4)}\left(q^{3 n+6} ; q^{6}\right)_{\frac{1}{2} n}^{2}}{\left(q^{3 n+1} ; q^{6}\right)_{\frac{1}{2} n}\left(q^{3 n+5} ; q^{6}\right)_{\frac{1}{2} n}} .
$$


Proof. We begin by observing that the $i$ th term in (37) must be zero unless $i$ is a multiple of 6 . Therefore

$$
\begin{aligned}
L_{q}(n) & =\sum_{i=0}^{n} \frac{q^{\mu(n, 6 i)}}{\left[\begin{array}{c}
6 n \\
6 i
\end{array}\right]}\left\{\left[y^{6 i}\right]\left(y^{3} ; q^{3}\right)_{2 n}\right\}\left\{\left[y^{6 i}\right]\left(y^{2} ; q^{2}\right)_{3 n}\right\} \\
& \left.=\sum_{i=0}^{n} \frac{(-1)^{i} q^{\mu(n, 6 i)}}{\left[\begin{array}{c}
6 n \\
6 i
\end{array}\right]}\left[\begin{array}{c}
2 n \\
2 i
\end{array}\right]_{3}\left[\begin{array}{c}
3 n \\
3 i
\end{array}\right]_{2} q^{3(2 i} \begin{array}{c}
2 i \\
2
\end{array}\right)+2\left(\begin{array}{c}
3 l \\
2
\end{array}\right) \\
& =\sum_{i=0}^{n}(-1)^{i} q^{\mu(n, 6 i)+15 i^{2}-6 i} \frac{\left[\begin{array}{c}
2 n \\
2 i
\end{array}\right]_{3}\left[\begin{array}{c}
3 n \\
3 i
\end{array}\right]_{2}}{\left[\begin{array}{c}
6 n \\
6 i
\end{array}\right]} .
\end{aligned}
$$

If $n$ is odd, then by (35), the $i$ th terms and the $(n-i)$ th terms cancel. Therefore $L_{q}(n)=0$ if $n$ is odd. If $n$ is even, then by (36) and (39)

$$
\begin{aligned}
L_{q}(n) & =\sum_{l=0}^{n} q^{6 l((\gamma-n) / 2-1)} \frac{\left(q^{-6 n} ; q^{3}\right)_{2 l}\left(q^{-6 n} ; q^{2}\right)_{3 l}(q)_{6 l}}{\left(q^{2} ; q^{2}\right)_{3 l}\left(q^{3} ; q^{3}\right)_{2 i}\left(q^{-6 n}\right)_{6 l}} \\
= & \sum_{l=0}^{n} \frac{\left(q^{-6 n} ; q^{6}\right)_{i}\left(q^{-6 n+3} ; q^{6}\right)_{l}\left(q^{-6 n} ; q^{6}\right)_{i}\left(q^{-6 n+2} ; q^{6}\right)_{i}\left(q^{-6 n+4} ; q^{6}\right)_{i}}{\left(q^{2} ; q^{6}\right)_{i}\left(q^{4} ; q^{6}\right)_{i}\left(q^{6} ; q^{6}\right)_{i}\left(q^{3} ; q^{6}\right)_{l}\left(q^{6} ; q^{6}\right)_{l}} \\
& \times q^{6 i((\gamma-n) / 2-1)} \frac{\left(q ; q^{6}\right)_{i}\left(q^{2} ; q^{6}\right)_{l}\left(q^{3} ; q^{6}\right)_{i}}{\left(q^{-6 n} ; q^{6}\right)_{l}\left(q^{-6 n+1} ; q^{6}\right)_{l}\left(q^{-6 n+2} ; q^{6}\right)_{i}} \\
& \times \frac{\left(q^{4} ; q^{6}\right)_{l}\left(q^{5} ; q^{6}\right)_{i}\left(q^{6} ; q^{6}\right)_{i}}{\left(q^{-6 n+3} ; q^{6}\right)_{l}\left(q^{-6 n+4} ; q^{6}\right)_{i}\left(q^{-6 n+5} ; q^{6}\right)_{l}} \\
= & { }_{3} \phi_{2}\left(q^{-6 n}, q, q^{5} ; q^{6}, q^{3(\gamma-n)-6}\right) \\
= & q^{(3 / 2) n(\gamma-4)} \frac{\left(q^{3 n+6} ; q^{6}\right)_{n / 2}\left(q^{3 n+6} ; q^{6}\right)_{n / 2}}{\left(q^{3 n+1} ; q^{6}\right)_{n / 2}\left(q^{3 n+5} ; q^{6}\right)_{n / 2}}
\end{aligned}
$$

by (8). Hence Theorem 5.1 has been established.

6. Concluding remarks. The proofs of the theorems in $\S \S 3-5$ rely on the reduction of certain $q$-binomial coefficient sums to ${ }_{3} \phi_{2}$ 's using the methods outlined in $\S 5$ of [1], and, in particular, the application of Theorem 5.1. The summands which occur with index $i$ in the $q$-analogue of Lemma 2.2 have the form

$$
\frac{\left[\begin{array}{c}
r n-s \\
r i-t
\end{array}\right]_{r^{\prime}}\left[\begin{array}{c}
j n-u \\
j i-v
\end{array}\right]_{j^{\prime}}}{\left[\begin{array}{c}
k n-w \\
k i-y
\end{array}\right]}
$$

It is therefore clear that the simplest $q$-hypergeometric series are obtained with $r r^{\prime}=j \quad j^{\prime}=k$, to ensure the most extensive cancellation of factors after normalisation. However, factors of the form $\left(q^{a} ; q^{k}\right)_{i}$ cannot be cancelled if $(a, k)=1$, so there will be at least $\phi(k)$ (where 
$\phi$ is Euler's totient function) entries in the numerator of the resulting $m \phi_{m-1}$ corresponding to the reduced residue class modulo $k$. Thus, the only ways the ${ }_{3} \phi_{2}$ summations of $\S 2$ can be applied is with $\phi(k)<4$, so $k=1,2,3,4,6$. Examination of these shows that the truly nontrivial cases occur for $\phi(k)=2$, in which case $k=3$, 4,6 . These are indeed the instances of $k$ we have considered. Other examples for $k=3,4,6$ can be derived following our methods, and we have merely provided a sample.

Acknowledgments. The authors wish to thank P. Edelman, F. Goodman and J. Stembridge for useful conversations about questions arising from this work. Part of this work was carried out while the authors were visitors at the Institute for Mathematics and its Applications, University of Minnesota, Minneapolis, during March 1988. One of us (GEA) would like to thank the Department of Combinatorics and Optimization for the use of its facilities during his visit to the department, as an Adjunct Professor, during which much of this work was done. This work was supported by grants from the National Science Foundation (DMS-8503324) and the Natural Sciences and Engineering Research Council of Canada (A-8235).

\section{REFERENCES}

[1] G. E. Andrews, Applications of basic hypergeometric functions, S.I.A.M. Review, 16 (1974), 441-484.

[2] _ Problems and prospects for basic hypergeometric functions, In: Theory and Application of Special Functions, R. Askey ed., Academic Press, New York, 1975, 191-224.

[3] - The Theory of Partitions, Encyclopedia of Mathematics and its Applications, Vol. 2, Addison-Wesley, London, 1976.

[4] D. M. Bressoud, Almost poised basic hypergeometric series, Ramanujan Centenary Issue of Proc. Indian Acad. Sci., (to appear).

[5] L. Carlitz, Some formulas of F. H. Jackson, Monat. für Math., 73 (1969), 193198.

[6] I. P. Goulden and D. M. Jackson, Combinatorial Enumeration, Wiley, New York, 1983.

[7] D. M. Jackson, Counting cycles in permutations by group characters, with an application to a topological problem, Trans. Amer. Math. Soc., 299 (1987), 785801.

[8] _ Counting semiregular permutations which are products of a full cycle and an involution, Trans. Amer. Math. Soc., 305 (1988), 317-331.

[9] F. H. Jackson, Certain q-identities, Quart. J. Math., 12 (1941), 167-172.

[10] G. Lusztig, On a theorem of Benson and Curtis, J. Algebra, 71 (1981), 490-498. 
[11] J-P. Serre, Linear Representation of Finite Groups, Springer-Verlag, New York, 1977.

[12] H. Wenzl, Hecke algebras of type $A_{n}$ and subfactors, (preprint).

Received June 4, 1988 and in revised form May 24, 1989.

Pennsylvania State University

UNIVERSITY PARK, PA 16802

AND

UNIVERSITY OF WATERLOO

Waterloo, Ontario, Canada 2NL 3G1 


\section{PACIFIC JOURNAL OF MATHEMATICS EDITORS}

\author{
V. S. VARADARAJAN \\ (Managing Editor) \\ University of California \\ Los Angeles, CA 90024-1555-05 \\ Herbert Clemens \\ University of Utah \\ Salt Lake City, UT 84112 \\ THOMAS ENRIGHT \\ University of California, San Diego \\ La Jolla, CA 92093
}

R. FINN

Stanford University

Stanford, CA 94305

Hermann Flaschka

University of Arizona

Tucson, AZ 85721

VAUGHAN F. R. Jones

University of California

Berkeley, CA 94720

Steven Kerckhoff

Stanford University

Stanford, CA 94305

\author{
C. C. MOORE \\ University of California \\ Berkeley, CA 94720
}

MARTIN SCHARLEMANN

University of California

Santa Barbara, CA 93106

HAROLd STARK

University of California, San Diego

La Jolla, CA 92093

\section{ASSOCIATE EDITORS}
R. ARENS
E. F. BECKENBACH
B. H. NeUmanN
F. WoLF
(1904-1989)
K. YosHIDA
(1906-1982)

\section{SUPPORTING INSTITUTIONS}

UNIVERSITY OF ARIZONA
UNIVERSITY OF BRITISH COLUMBIA
CALIFORNIA INSTITUTE OF TECHNOLOGY
UNIVERSITY OF CALIFORNIA
MONTANA STATE UNIVERSITY
UNIVERSITY OF NEVADA, RENO
NEW MEXICO STATE UNIVERSITY
OREGON STATE UNIVERSITY

UNIVERSITY OF ARIZONA

CAIVERSITY OF BRITISH COLUN UNIVERSITY OF CALIFORNIA

MONTANA STATE UNIVERSITY OREGON STATE UNIVERSITY

\author{
UNIVERSITY OF OREGON \\ UNIVERSITY OF SOUTHERN CALIFORNIA \\ STANFORD UNIVERSITY \\ UNIVERSITY OF HAWAII \\ UNIVERSITY OF TOKYO \\ UNIVERSITY OF UTAH \\ WASHINGTON STATE UNIVERSITY \\ UNIVERSITY OF WASHINGTON
}

The Supporting Institutions listed above contribute to the cost of publication of this Journal, but they are not owners or publishers and have no responsibility for its content or policies.

Mathematical papers intended for publication in the Pacific Journal of Mathematics should be in typed form or offset-reproduced (not dittoed), double spaced with large margins. Please do not use built up fractions in the text of the manuscript. However, you may use them in the displayed equations. Underline Greek letters in red, German in green, and script in blue. The first paragraph must be capable of being used separately as a synopsis of the entire paper. In particular it should contain no bibliographic references. Please propose a heading for the odd numbered pages of less than 35 characters. Manuscripts, in triplicate, may be sent to any one of the editors. Please classify according to the 1980 Mathematics Subject Classification (1985 Revision) scheme which can be found in the December index volumes of Mathematical Reviews. Supply name and address of author to whom proofs should be sent. All other communications should be addressed to the managing editor, or Elaine Barth, University of California, Los Angeles, California 90024-1555-05.

There are page-charges associated with articles appearing in the Pacific Journal of Mathematics. These charges are expected to be paid by the author's University, Government Agency or Company. If the author or authors do not have access to such Institutional support these charges are waived. Single authors will receive 50 free reprints; joint authors will receive a total of 100 free reprints. Additional copies may be obtained at cost in multiples of 50 .

The Pacific Journal of Mathematics (ISSN 0030-8730) is published monthly. Regular subscription rate: $\$ 190.00$ a year (12 issues). Special rate: $\$ 95.00$ a year to individual members of supporting institutions.

Subscriptions, orders for numbers issued in the last three calendar years, and changes of address should be sent to Pacific Journal of Mathematics, P.O. Box 969, Carmel Valley, CA 93924, U.S.A. Old back numbers obtainable from Kraus Periodicals Co., Route 100, Millwood, NY 10546.

The Pacific Journal of Mathematics at P.O. Box 969, Carmel Valley, CA 93924 (ISSN 0030-8730) is published monthly. Second-class postage paid at Carmel Valley, California 93924, and additional mailing offices. Postmaster: send address changes to Pacific Journal of Mathematics, P.O. Box 969, Carmel Valley, CA 93924.

\section{PUBLISHED BY PACIFIC JOURNAL OF MATHEMATICS, A NON-PROFIT CORPORATION}




\section{Pacific Journal of Mathematics}

Vol. 144, No. $2 \quad$ June, 1990

George E. Andrews and David M. Jackson, An algebraically derived $q$-analogue of a character sum associated with a class of semiregular

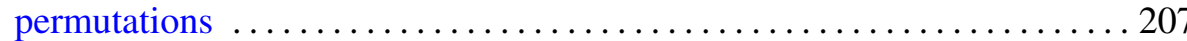

Fabio Bardelli and Andrea Del Centina, The moduli space of genus four double covers of elliptic curves is rational $\ldots \ldots \ldots \ldots \ldots \ldots \ldots \ldots 219$

Young Do Chai, An estimate of the volume of a compact set in terms of its

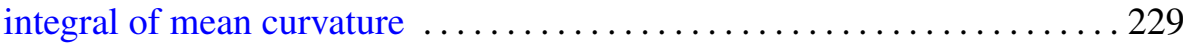

Salvador Comalada, Elliptic curves with trivial conductor over quadratic fields

Kahar El-Hussein, Résolubilité semi-globale des opérateurs différentiels invariants sur les groupes de déplacements $\ldots \ldots \ldots \ldots \ldots \ldots \ldots \ldots . \ldots 259$

David M. Goldschmidt, Classical link invariants and the Burau representation

Liliana Janicka, Radon-Nikodým problem for the variation of a vector measure

Wacław Marzantowicz, An almost classification of compact Lie groups with Borsuk-Ulam properties ............................ 299

Akira Ohbuchi, On the projective normality of some varieties of degree 5 . . 313 Ken'ichi Ohshika, Minimal measured laminations in geometric

3-manifolds

Hal Leslie Smith, A discrete Lyapunov function for a class of linear differential equations

John Samuel Spielberg, Diagonal states on $O_{2} \ldots \ldots \ldots \ldots \ldots \ldots \ldots \ldots$

Thomas Vogel, A note on the sessile drop

Gerold Wagner, On means of distances on the surface of a sphere (lower bounds) 